\title{
Dependence of surface roughness on technological conditions of ultrasonic smoothing
}

\author{
V.I. Malygin, L.V. Kremleva*, N.S. Oblovatskaya, N.V. Lobanov \\ Institute of Shipbuilding and Marine Arctic Technology \\ Northern (Arctic) Federal University named after M.V. Lomonosov, NArFU \\ Severodvinsk, Russian Federation \\ *L.Kremleva@narfu.ru
}

\begin{abstract}
Fatigue, corroding and tribological properties of machine parts are mostly determined by surface quality formed during finishing operations. One of the most effective ways to form the required surface is by ultrasonic smoothing. The article presents experimental results of ultrasonic surface smoothing for workpieces of two types of steels 17X18N9T and 20X1M1F1TR. The experiments were conducted on the turning lathe with the experimental ultrasonic technological complex. The variables were workpiece rotational speed, feeding speed, clamping force and ultrasonic power treatment. D-optimal plan of Hartley-Kono was used during the experiment. Dispersion-regressive analysis of the experimental data revealed the relation between the surface roughness and processing regime modes. Feeding lowering decreases the surface roughness for both steels. To decrease the surface roughness of $20 X 1 M 1 F 1 T R$ steel it is necessary to increase power of ultrasonic treatment simultaneously with clamping force decrease. For steel 17X18N9T clamping force results in surface roughness lowering that is why ultrasonic power is not significant. Partial correlation coefficient analysis revealed that micro profile height for steel 20X1M1F1TR is determined by feeding speed. For austenitic steel 17X18N9T feeding speed and clamping force are equally important factors. During the experiments the surface roughness decreased from 1.5 mkm to $0,1-0,2 \mathrm{mkm}$ with ultrasonic treatment, that is more than 10 times.
\end{abstract}

Keywords- ultrasonic smoothing, ultrasonic power output, indenter, plastic zone, surface roughness, processing modes.

\section{INTRODUCTION}

Surface quality determines utilization properties of the details. As it has been noted in [1,2] durability, corrosion and fatigue resistance of products, which are utilized in severe and corrosive environment are determined not only by rational constructions and physic-technical material properties but also depend on processing modes during finishing operations. Two parameter groups of surface quality are denoted [4, 10]: geometrical parameters and parameters determining physical surface properties. The detail surface is always rough due to its processing. Physic-mechanical properties of the facial layer are characterized by the degree of its firmness relative to the base workpiece material, degree and character of the residual internal stress, micro cracks and other parameters. One of the methods providing stable and favorable surface quality is method of ultrasonic finish processing [3, 4] known as ultrasonic smoothing.

Numerous Russian and foreign studies are devoted to surface plastic deformation with ultrasound [4, 5, 6]. Vibro machining by surface-plastic deformation leads to metal facial layer hardening. In [2, 3] it is stated that maximal values of normal and share stresses in deformation zone influence quality parameters of metal pressure final processing. During ultrasonic treatment static force, providing physical contact between the indenter and machined surface, displacement amplitude at the given vibration speeds determine the degree of stresses, deformation speed of the facial layers. The force action in ultrasonic frequency results in grain displacement, their form change, crushing. It influences material physicmechanical properties; increases fatigue resistance, yield limits and strength, wear resistance $[7,8,16]$. As works [11, 14] present data on wear resistance, crack resistance, fatigue surface resistance increase with ultrasound treatment at high temperatures, during coating [12], during bead-blasting [13]. Authors in [5] studying the issues of energy consumption for lattice distortion note significant influence of plastic deformation spreading speed in the workpiece facial layers. It is especially interesting to solve problems of nano-crystalic structure creation in surface layers of the important metal goods [15, 16]. In work [15], during impact by ultrasonic frequency $20-25 \mathrm{kHz}$ with cylindrical indenters, freely moving axially along the normal to the machined surface with the impact strength $0,3-0,9 \mathrm{\kappa Gm}$ and local heating in the contact place $300-500 \mathrm{C}^{0}$, a nano-crystalic structure in the facial layer at the depth $1 \mathrm{~mm}$ and sub-micro-crystalic structure at the depth from 1 to $2 \mathrm{~mm}$, improving physicmechanical material characteristics,-- such as strength, hardness and micro hardness increases detail durability by nanocrystalic structure depth increase and surface pressing stresses. It allows enhancing constructional steels and alloys qualities, for example, titan ones, up to the qualities of tools steels.

It is known that during cutting surface roughness is formed as a geometric trace of the working movement of the cutter relative to the workpiece. Occasional and systematic inequalities in the profile depend on relation of technological factors, influencing micro relief formation. Irregularity 
coefficient $k_{z}$ can be a measure of occasional inequalities in the profile micro relief, which is determined as relation of roughness height root-mean-square deviation of a random component and the whole profile. According to [6] for grinding and milling $k_{z}=0.2 \div 0.9$, grinding $k_{z}=0.7 \div 0.9$, smooth finish and polishing $k_{z}=0.8 \div 0.9$, vibro smoothing и vibro rolling $k_{z}=0.15 \div 0.3$. Herewith, the main parameters influencing surface roughness received by vibro smoothing are technological modes of processing, tool geometry, intensity and capacity of ultrasonic impact and other parameters. Great homogeneity of the surface micro relief, received by surface plastic deformation gives big possibilities for production surfaces with highly-homogenous micro relief. In this case micro relief is considered a regulated system [2, 3], influenced by external ultrasonic impact with the specified regulated parameters, determining an effect of enhanced service properties of machine parts. By trial and error of technological parameters we can reduce surface roughness and enhance surface smoothness 4-8 times [9, 10]. Surface smoothing by vibro treatment has several advantages comparing with other surface-plastic deformation processes by productivity, simplicity, and universality of utilization.

Herewith, technological equipment should provide process stability, compensating indenter wear under dynamic force and temperature [8].

Surface smoothing by vibro treatment has several advantages comparing with other surface-plastic deformation processes by productivity, simplicity, and universality of utilization.

Besides, surface-plastic deformation with vibro treatment results in prominent metal facial hardening. It should be noted that experimental data on surface quality parameters can be applied only to a small number of applied materials and goods. Recommendations on technological modes in the above mentioned works can be applied to treatment of strong, tough corrosion resistance steels and alloys, widely applied in shipbuilding. The aim of this work was to study dependence of surface roughness on ultrasonic finish machining, technological modes of details made from ship building materials. As steel types used in ship building, rust-resistant austenite steel 17X18N9 (S30200, the USA), and heat resistance relaxation resistant perlite steel 20X1M1F1TR were chosen.

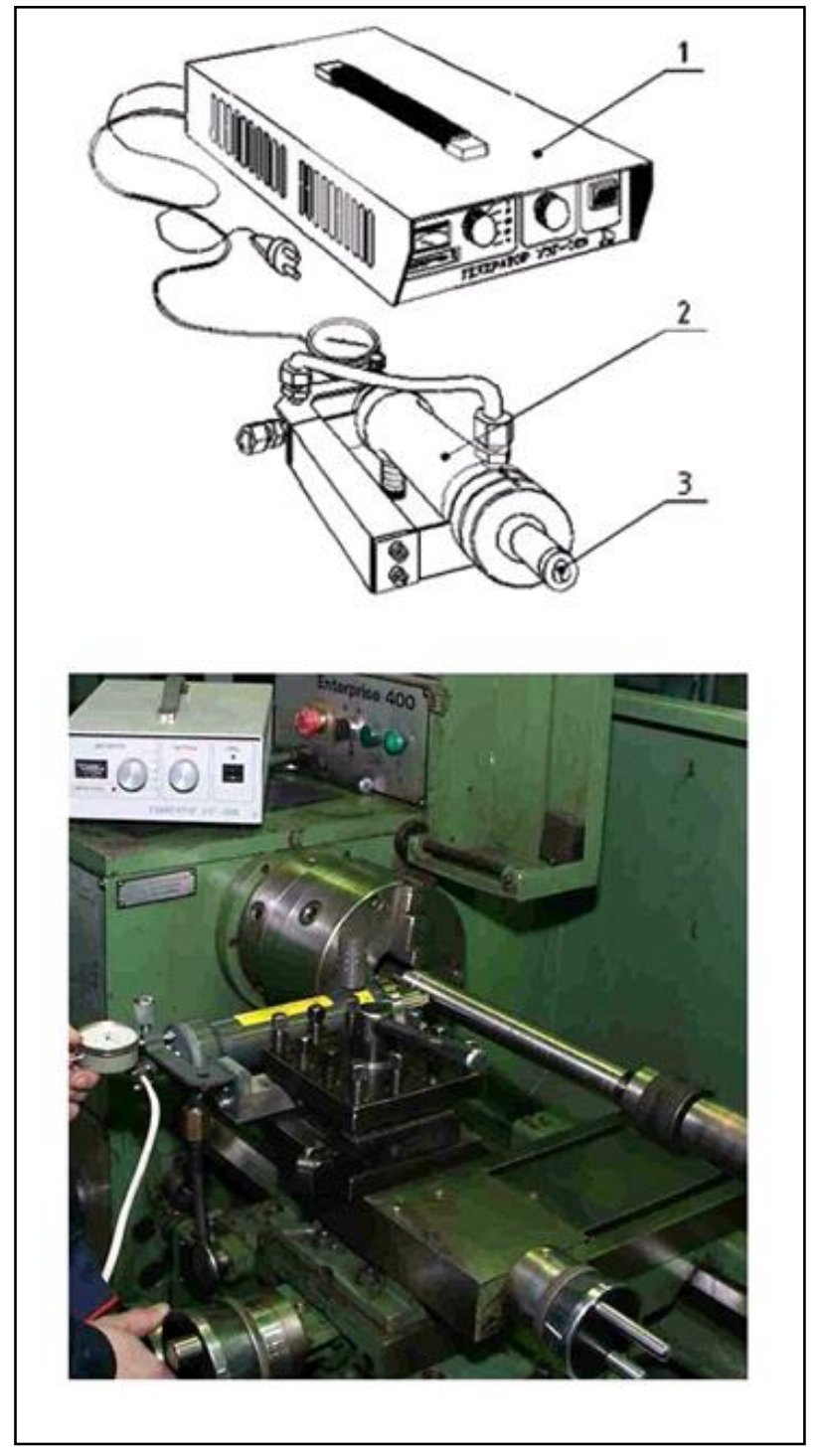

Fig. 1. Experimental unit: 1 - generator UZG-04M1, 2 - ultrasonic head, 3 hard-alloy indenter.

\section{METHODS OF EXPERIMENTAL RESEARCH}

Experimental tests were conducted on the lathe ENTERPRISE 400 in laboratory environment with the application of experimental ultrasonic technological complex (UTC). The UCT consists of: the generator UZG-04M1, an ultrasonic head with magnetostriction permendur transducer $49 \mathrm{~K} 2 \mathrm{~F} 1$, titan alloy duct PT-3C and hard alloy indenter with the working part made of alloy T5K10 diameter $6 \mathrm{~mm}$. The ultrasonic head was fixed to the lathe carriage with the fixing device. The general view of the experimental unit is given in Figure 1.

Generator UZG-04M1 with capacity $0,25 \mathrm{kWt}$, for line voltage $50 \mathrm{~Hz}$ transformation into operational voltage of magnetostriction transducer wind $22 \mathrm{kHz}$, was the source of power and resonance frequency locked-loop for the transducer. The generator had a staged system of processing energy switching. 
Cylindrical workpieces of steel 17X18N9 and 20X1M1F1TR diameter $35 \mathrm{~mm}$ and length $300 \mathrm{~mm}$ with the initial roughness $\mathrm{Ra}=1 \ldots 2 \mathrm{mkm}$ were under ultrasonic finish treatment. As lubricating cooling liquid industrial oil IGP-38 was used. The influence of feeding $S$, spindle rotational speed $n$, indenter steady-state fixing $P$ and generator capacity $N$ on surface roughness has been studied in the work. Steady state fixing force was created by ultrasonic head spring and was recorded with the point indicator. To reduce number of experiments $D$-optimal plan of Hartley-Kono was used for factors number $p=4$ [17]. Experimental plan, natural and coded values of factors are given in Table 1. Variation ranges of the chosen technological factors were determined by test experiments. The choice of the strain low value $P$ was based on that at $P<20 \mathrm{H}$ the load does not lessen surface roughness, and the upper value of $\mathrm{P}$ is limited by indenter strength. The choice of the feeding variation range was based on geometry, when $S>0.2 \mathrm{~mm} /$ rot there is no overlapping of "plastic" tool traces, and when $S<0.04 \mathrm{~mm} /$ rot surface quality worsens due to large degree of overlapping. The upper limit of spindle rotational speed is limited by vibration occurrence.

When the workpiece was centered due to technological system stiffness inequality along the workpiece, indenter wear, and other factors influence surface roughness were not constant and changed along the workpiece. To determine roughness change along the workpiece due to the technological system stiffness change four experiments were conducted (two for every steel type), when the workpieces were machined on the lathe, tuned for machining in the ultrasonic field constant dead head position and tail spindle outlet, as well as front center position fixed in a 3-cammed chunk. Then the surface roughness was measured on different segments along the workpiece. It was determined that the surface roughness change from the front center to the back one goes according the linear law and increases in average on $13.4 \%$ for steel 20X1M1F1TR and $11.3 \%$ for steel 17X18N9T. To estimate indenter tooth contact with the workpiece during ultrasonic smoothing workpiece static lengthwise deflections under static impact was done. The load was done with the ultrasonic head. The deformations were measured with electronic device "Length gauge EDK 87" with accuracy $0,0001 \mathrm{~mm}$. During measurements the following rigidity mean values were received: $12.6104 \mathrm{H} / \mathrm{mm}$ at the front center and $10.2104 \mathrm{H} / \mathrm{mm}$ at the back center, that is rigidity variation along the workpiece was about $20 \%$. To compensate deflections the surface roughness was measured at 18 segments along the workpiece before the ultrasonic treatment and after (picture 2). For this the roughness was measured after ultrasonic smoothing with the profilometer Surtronic-3. Then the workpiece was fixed to the lathe again and ground to remove cold work layer from ultrasound impact to the smoothness $1.2 \mathrm{mkm}$. After that the technological cycle was repeated, till the workpiece diameter was $32 \mathrm{~mm}$. During regression analysis the mathematical expectation was applied (average) of the measured value $R a$ to the results of 18 measurements.

To receive mathematical models of surface roughness dependence on technological parameters linear regression analysis was conducted. Model correctness was checked by
Fisher's criteria at 5\%-level of significance, and coefficients significance by Student's criteria. All insignificant coefficients were excluded.

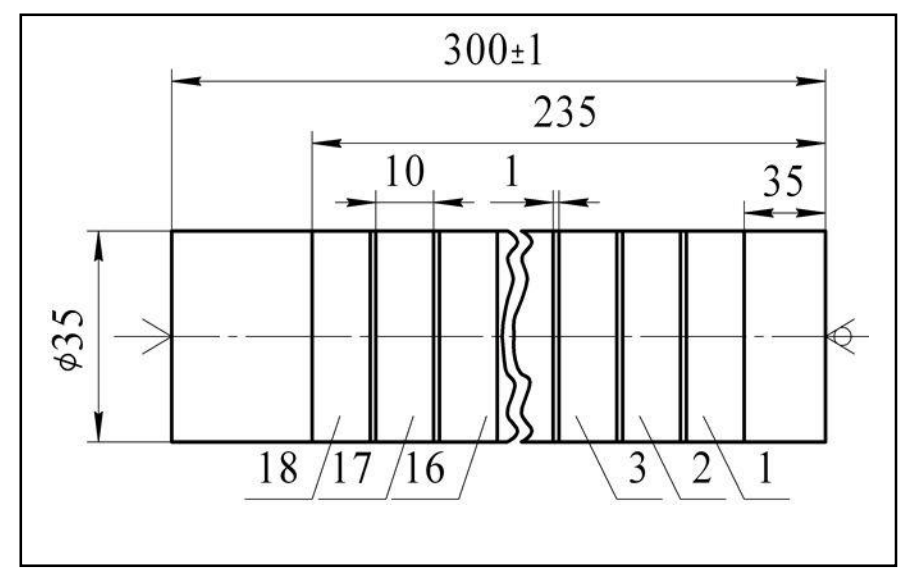

Fig. 2. Zones of roughness measurement along the cylindrical workpiece.

Also, correlation coefficients between surface roughness and steel parameters of both types were studied.

\section{RESULTS OF THE STUDY AND DISCUSSION}

Table 1 shows natural and standardized values of variable parameters and measured surface roughness values.

The statistical data processing for steel 20X1M1F1TR gave the following regression models for natural parameters $\left(R^{2}=0.74, F=9.1\right)$ :

$$
R a=0.075+1.948 \cdot S+0.0013 \cdot P-0,001 \cdot N
$$

Similar dependences for steel $17 \mathrm{X} 18 \mathrm{~N} 9 \mathrm{~T}$ have the view $\left(R^{2}=0.49, F=3.1\right)$ :

$$
R a=0,358+0.557 \cdot S-0.002 \cdot P
$$

In equations (1-2): $S$ - feeding, $\mathrm{mm} / \mathrm{rot} ; P$ - indenter clamping force to the workpiece, $\mathrm{H} ; \mathrm{N}$ - generator power, Watt.

For both steels feed increase results in surface roughness increase. While for steel 20X1M1F1TR feed increase is more significant. Ultrasonic power increase results in micro relief thinning for steel 20X1M1F1TR. For this steel dynamic and static load is reverse: static load increase $\mathrm{P}$ results in roughness increase, power increase leads to roughness lowering. During machining of the steel workpieces 17X18N9T static clamping force increase results in surface roughness lowering. The change of the peripheral rotation speed of the machined surface does not influence facial layer characteristics, as shock loads number per unit of the machined surface at operational rotation speeds and ultrasonic vibrations frequency is so great that plastic deformation process goes up to complete saturation [9]. 
TABLE I. EXPERIMENT PLAN AND RESULTS

\begin{tabular}{|c|c|c|c|c|c|c|c|c|c|}
\hline \multirow{3}{*}{ № } & \multicolumn{8}{|c|}{$\begin{array}{l}\text { Ultrasonic treatment results, } \\
\text { steel 20X1M1F1TR } \\
\text { steel 17X18N9T }\end{array}$} & \multirow{3}{*}{$\begin{array}{c}R a, \\
\text { mkm }\end{array}$} \\
\hline & \multicolumn{4}{|c|}{ Natural values } & \multicolumn{4}{|c|}{ Standardized values } & \\
\hline & $\underset{m / m i n}{V,}$ & $\underset{t}{S,}$ & $\begin{array}{l}\boldsymbol{P}, \\
\boldsymbol{H}\end{array}$ & $\begin{array}{c}N, \\
W t\end{array}$ & $\begin{array}{c}X 1, \\
n\end{array}$ & $\begin{array}{c}X 2 \\
S\end{array}$ & $\begin{array}{c}X 3, \\
P\end{array}$ & $\begin{array}{c}X 4, \\
N\end{array}$ & \\
\hline \multirow{2}{*}{1} & 180 & $\underline{0.04}$ & $\underline{80}$ & $\underline{88}$ & 1 & -1 & -1 & $\underline{-1}$ & $\underline{0.13}$ \\
\hline & 125 & $\overline{0.045}$ & 80 & $\overline{176}$ & -1 & -1 & -1 & 1 & 0.10 \\
\hline \multirow{2}{*}{2} & $\underline{63}$ & $\underline{0.16}$ & $\underline{80}$ & $\underline{88}$ & -1 & 1 & -1 & -1 & $\underline{0.26}$ \\
\hline & 630 & 0.045 & 80 & 88 & 1 & -1 & 1 & -1 & 0.26 \\
\hline \multirow{2}{*}{3} & $\underline{63}$ & $\underline{0.04}$ & 160 & $\underline{88}$ & -1 & $\underline{-1}$ & $\underline{1}$ & $\underline{-1}$ & $\underline{0.4}$ \\
\hline & 125 & 0.045 & 160 & 176 & -1 & -1 & 1 & 1 & 0.04 \\
\hline \multirow{2}{*}{4} & 180 & $\underline{0.16}$ & 160 & $\underline{88}$ & 1 & 1 & 1 & $\underline{-1}$ & $\underline{0.53}$ \\
\hline & 630 & 0.045 & 160 & 88 & 1 & -1 & 1 & -1 & 0.12 \\
\hline \multirow{2}{*}{5} & 180 & 0.04 & $\underline{80}$ & 176 & 1 & -1 & -1 & 1 & 0.1 \\
\hline & 630 & 0.045 & 120 & 176 & 1 & -1 & 0 & 1 & 0.13 \\
\hline \multirow{2}{*}{6} & $\underline{63}$ & $\underline{0.16}$ & $\underline{80}$ & 176 & -1 & 1 & -1 & 1 & $\underline{0.35}$ \\
\hline & $\overline{315}$ & $\overline{0.25}$ & $\overline{160}$ & $\overline{176}$ & $-0 . \overline{24}$ & -1 & 1 & 1 & $\overline{0.08}$ \\
\hline \multirow{2}{*}{7} & $\underline{63}$ & 0.04 & 160 & 176 & $\underline{-1}$ & -1 & 1 & 1 & $\underline{0.08}$ \\
\hline & 630 & 0.25 & 80 & 132 & 1 & -1 & -1 & 0 & 0.15 \\
\hline \multirow{2}{*}{8} & 180 & $\underline{0.16}$ & 160 & $\underline{176}$ & $\underline{1}$ & $\underline{1}$ & $\underline{1}$ & $\underline{1}$ & 0.36 \\
\hline & 125 & 0.25 & 80 & 88 & -1 & 1 & -1 & -1 & 0.46 \\
\hline \multirow{2}{*}{9} & $\underline{125}$ & $\underline{0.1}$ & 120 & 132 & 0.06 & $\underline{0}$ & $\underline{0}$ & $\underline{0}$ & $\underline{0.26}$ \\
\hline & 630 & 0.25 & 80 & 176 & 1 & 1 & -1 & 1 & 0.48 \\
\hline \multirow{2}{*}{10} & $\underline{125}$ & $\underline{\underline{0.16}}$ & $\underline{80}$ & $\underline{176}$ & $\underline{0.06}$ & $\underline{1}$ & $\underline{-1}$ & $\underline{1}$ & $\underline{0.33}$ \\
\hline & 125 & 0.25 & 160 & 88 & -1 & 1 & 1 & -1 & 0.46 \\
\hline \multirow{2}{*}{11} & $\underline{63}$ & 0.1 & $\underline{80}$ & $\underline{88}$ & -1 & $\underline{0}$ & -1 & -1 & 0.07 \\
\hline & 630 & 0.25 & 160 & 176 & $\overline{1}$ & 1 & $\overline{1}$ & 1 & 0.15 \\
\hline \multirow{2}{*}{12} & $\underline{180}$ & 0.1 & 160 & 176 & 1 & $\underline{0}$ & 1 & 1 & $\underline{0.15}$ \\
\hline & 125 & 0.25 & 160 & 132 & -1 & 1 & 1 & 0 & 0.12 \\
\hline \multirow{2}{*}{13} & $\underline{63}$ & 0.16 & $\underline{80}$ & 132 & -1 & 1 & -1 & $\underline{0}$ & 0.39 \\
\hline & 125 & 0.14 & 120 & 88 & -1 & 1 & 0 & -1 & 0.17 \\
\hline \multirow{2}{*}{14} & 63 & $\underline{0.1}$ & 160 & $\underline{176}$ & $\underline{-1}$ & $\underline{0}$ & $\underline{1}$ & $\underline{1}$ & $\underline{0.25}$ \\
\hline & 630 & $\overline{0.14}$ & $\overline{80}$ & 132 & $\overline{1}$ & 1 & -1 & 0 & $\overline{0.30}$ \\
\hline \multirow{2}{*}{15} & 125 & $\underline{0.16}$ & 160 & $\underline{88}$ & $\underline{0.06}$ & 1 & $\underline{1}$ & -1 & $\underline{0.43}$ \\
\hline & $\overline{315}$ & $\overline{0.14}$ & $\overline{120}$ & $\overline{132}$ & $-\overline{-0.24}$ & $-0 . \overline{0} 73$ & $\overline{0}$ & $\overline{0}$ & $\overline{0.15}$ \\
\hline \multirow{2}{*}{16} & 180 & $\underline{0.04}$ & 160 & 132 & 1 & 1 & 1 & $\underline{0}$ & $\underline{0.06}$ \\
\hline & 125 & 0.14 & 80 & 88 & -1 & -0.073 & -1 & -1 & 0.16 \\
\hline \multirow{2}{*}{17} & $\underline{180}$ & $\underline{0.04}$ & 120 & 170 & 1 & $\underline{-1}$ & $\underline{0}$ & 1 & 0.04 \\
\hline & 630 & 0.14 & 160 & $\overline{176}$ & $\overline{1}$ & -0.073 & $\overline{1}$ & $\overline{1}$ & $\overline{0.09}$ \\
\hline \multirow{2}{*}{18} & 125 & 0.04 & 160 & 88 & 0.06 & -1 & 1 & -1 & 0.32 \\
\hline & 630 & 0.14 & 160 & 88 & 1 & -0.073 & 1 & -1 & 0.10 \\
\hline
\end{tabular}

Determining pair correlation coefficients between surface roughness and regime modes showed that for steel 20X1M1F1TR coefficients with feeding speed are significant $S(k=0.82)$, At the same time for steel $17 \mathrm{X} 18 \mathrm{~N} 9 \mathrm{~T}$ correlation coefficients between roughness and feeding $\mathrm{S}$ and clamping force $P$ are equal correspondingly 0.44 and -0.51 . The received results correlate satisfactory with the results in $[3,8]$, according to which feeding increase results in surface increase nearly proportionally, and increase of ultrasonic emission results in micro roughness's thinning. On the one hand, clamping force increase results in indenter tooth contact with the workpiece, as well as area and depth of plastic deformation, which leads to smoothing initial rough surface. On the other hand, from the geometrical point of view feeding increase results in micro roughness increase.

It should be noted that during all the experiments vibration level during ultrasonic smoothing was much lower than during turning or cold-work layer removal. It is connected with the peculiarities of ultrasonic treatment, when developed plastic deformation zone increases significantly damping in the technological system occurs. It can explain the following works [9], where during ultrasonic smoothing there is a possibility to receive minimal surface roughness on the nonrigid equipment.

The indenter clamping force $\mathrm{P}$ influences the location of plastic deformation, ultrasonic impact power $\mathrm{N}$ and the indenter diameter. These parameters influence form and size of indenter tooth contact with the workpiece, and consequently, facial layer microstructure characteristics, localization and direction of the surface strength. So, further investigations on physic-technical surface characteristics can be treated as promising.

\section{CONCLUSIONS}

As the result of investigation, technological parameters of the ultrasonic treatment are found, which decrease surface roughness from $1,5 \mathrm{mkm}$ to $0.1-0.2 \mathrm{mkm}$.

It is experimentally proved that feed increase results in surface roughness increase. To low the surface roughness of the perlite steel workpieces it is necessary to increase ultrasonic influence power with simultaneous clamping force lowering. For austenite steels clamping force increase results in the increase of the facial micro roughness, and ultrasonic power has no significant influence. These results correlate with those of ultrasonic smoothing of titanic alloys workpieces [18] and prove possibility of the method application for enhancing utilization qualities of the details and machine nods made of non-ferrous and ferrous metals and alloys. Suggested statistical models of roughness dependence on regime modes for two types of materials, allow determining rational operational conditions during ultrasonic smoothing.

\section{References}

[1] Yu. G. Shneyder, Finishing technology of pressure processing technology. St. Petersburg: Polytechnic Publ., 1996.

[2] Yu.G. Shneyder, Formation of regular microreliefs on details and their operational properties of details with a regular microrelief, St. Petersburg: Mashinostroenie Publ., 1982.

[3] A.G. Suslov, Quality of the surface layer of machine parts, Moscow: Mashinostroenie Publ., 2000.

[4] D.D. Papshev, Finishing-hardening treatment by surface-plastic deformation, Moscow: Mashinostroenie Publ., Moscow: Mashinostroenie Publ., 1978.

[5] X.Wu, N.Tao, Y. Hong, B.Xu , J. Lu , K. Lu, "Microstructure and evolution of mechanically-induced ultrafine grain in surface layer of AL-alloy subjected to USSP," Actamaterialia, vol. 50, no. 8, pp. 20752084, 2002.

[6] V.A. Gorokhov, Improving the operational properties of parts and tools by vibrating and vibro-smoothing methods, Moscow: Tsentral'noe upravlenie NTOmashprom Publ., 1983.

[7] V.P. Alekhin, Physics of Strength and Plasticity of Surface Layers of Materials, Moscow: Nauka Publ. , 1983.

[8] I. Markov, Ultrasonic processing of materials, Moscow: Mashinostroenie Publ.,1980.

[9] N.P. Kolomeets, Improvement of the properties of products from structural steels and alloys by the method of force action by an ultrasonic instrument. Ph.D. Thesis, Moscow, 2003. 
[10] A.A. Fedorov, D.A.Polonyankin, A.I.Blesman, D.V.Postnikov, "Research of AISI 321 steel microrelief after ultrasonic impact treatment with marker applying," IOP Conf. Series: Journal of Physics, Vol. 944, 2018. doi : 10.1088/1742-6596/944/1/012035

[11] A. Amanov, Y.S. Pyun, V.K. Vasudevan, "High Strength and Wear Resistance of Tantalum by Ultrasonic Nanocrystalline Surface Modificatio Technique at High Temperatures," Proc. IOP Conf. Series: Materials Science and Engineering, Vol. 194, 2017. doi:10.1088/1757899X/194/1/012032.

[12] S. Stanzl-Tschegg, "Fatigue crack growth and thresholds at ultrasonic frequencies," International Journal of Fatigue, Vol. 28, pp. 1456-1464, 2006.

[13] O.V. Burlachenko, D.P. Klochkova, "Increase of the Wear Resistance of Metal Details on the Basis of a Simultaneous Application of the HighTest Cover and Ultrasonic Vibrations," Inter. Conf. on Industrial Engineering, Procedia Engineering,Vol. 150, pp.442 - 447, 2016.

[14] V. Pandey, K. Chattopadhyay, V. Singh, N. C. Santhi Srinivas, "Effect of stress relieving treatment on low cycle fatigue behavior of USSP treated 7075 aluminium alloy,” IOP Conf. Series: Materials Science and Engineering, Vol. 194, 2017. doi:10.1088/1757-899X/194/1/012037.

[15] N.P. Kolomeets, "Ultrasonic intensification of plastic deformation in the creation of nanostructures of titanium alloys," The state of the nanoindustry infrastructure in the Arkhangelsk Region, Arkhangel'sk: Arkhangel'sk State Technical University Publ., 2009, p. 26-32.

[16] N.P. Koloneets, V.I. Malygin, V.I. Melekov, Method for hardening the cutting tool by nanostructuring, Patent RF, no. №2443537, 2012.

[17] V. V. Nalimov, T. I. Golikova, bases for experiment planning, Moscow: Metallurgiya, 1976.

[18] O.V. Taratynov, V.V. Poroshin, V.V. Kharchenko, "Calculations of machined surface's profile peaks height with an allowance for indentor imprints overlapping degree under ultrasonic machining," Russian Engineering Research, Vol. 33, no.1, pp. 53-56, 2013. doi: 10.3103/S1068798X13010103 